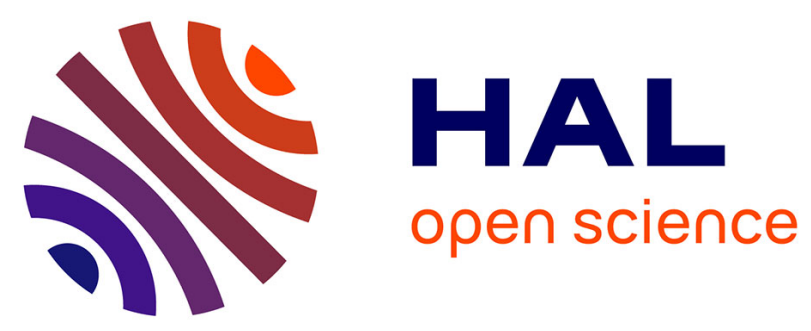

\title{
Precise Facet Temperature Distribution of High- Power Laser Diodes: Unpumped Window Effect
}

Jérémy Michaud, Pamela del Vecchio, Laurent Béchou, David Veyrié, Mauro Bettiati, François Laruelle, Stéphane Grauby

\section{- To cite this version:}

Jérémy Michaud, Pamela del Vecchio, Laurent Béchou, David Veyrié, Mauro Bettiati, et al.. Precise Facet Temperature Distribution of High- Power Laser Diodes: Unpumped Window Effect. IEEE Photonics Technology Letters, 2015, 27 (9), pp.1002-1005. 10.1109/LPT.2015.2405090 . hal-01155505

\section{HAL Id: hal-01155505 \\ https://hal.science/hal-01155505}

Submitted on 26 May 2015

HAL is a multi-disciplinary open access archive for the deposit and dissemination of scientific research documents, whether they are published or not. The documents may come from teaching and research institutions in France or abroad, or from public or private research centers.
L'archive ouverte pluridisciplinaire HAL, est destinée au dépôt et à la diffusion de documents scientifiques de niveau recherche, publiés ou non, émanant des établissements d'enseignement et de recherche français ou étrangers, des laboratoires publics ou privés. 


\title{
Precise Facet Temperature Distribution of High- Power Laser Diodes: Unpumped Window Effect
}

\author{
Jérémy Michaud, Pamela Del Vecchio, Laurent Béchou, David Veyrié, Mauro Andrea Bettiati, \\ Francois Laruelle, and Stéphane Grauby
}

\begin{abstract}
A thermoreflectance technique is used to evaluate the temperature variations at the output facet of high-power GaAs-based laser diodes emitting at $980 \mathrm{~nm}$. Two kinds of diodes with different unpumped windows (UPWs) are studied to determine the influence of UPW length on the temperature variation. We show that in the vicinity of the active region, where a catastrophic optical damage is most susceptible to occur, the short UPW diode heats much more (up to $40 \%$ ) than the long UPW one.
\end{abstract}

Index Terms-Catastrophic optical degradation, facet temperature variation, laser diode, unpumped window.

\section{INTRODUCTION}

$\mathbf{F}$ ACET heating, mainly due to laser light absorption and surface carrier recombination, plays a major role concerning laser diode reliability [1]. The heating reduction, in particular near the active region, can increase the current threshold of catastrophic optical degradation (COD) and consequently the maximum output optical power. Introducing an unpumped window (UPW) architecture is one of the possible strategies to reduce the facet temperature and hence fabricate highly reliable devices with high power operation [2], [3]. The UPW consists in a region located at the diode front facet where current injection is reduced.

In this letter, we study 980nm emitting laser diodes which constitute performing systems in terms of output power, conversion efficiency and reliability. Two kinds of laser diodes are compared, considering either a short or a long UPW. Very few studies of the UPW impact on the facet temperature are reported in literature and most of them are simulations [4] or measurements of the ridge temperature [5]. $\mu$-Raman facet measurements [6] can also be found but with large uncertainties and long acquisition times, which prevent this

This work was supported by the Centre National d'Etudes Spatiales.

J. Michaud and S. Grauby are with the Universite de Bordeaux, Laboratoire Ondes et Matière d'Aquitaine, Talence 33400, France (e-mail: jmichaud25@gmail.com; stephane.grauby@u-bordeaux.fr).

P. Del Vecchio, M. A. Bettiati, and F. Laruelle are with 3S Photonics, Nozay 91625, France (e-mail: pamela.delvecchio@ims-bordeaux.fr; mbettiati@3spgroup.com; flaruelle@3spgroup.com).

L. Béchou is with the Intégration du Matériau au Système, Université de Bordeaux, Talence 33405, France (e-mail: laurent.bechou@ims-bordeaux.fr).

D. Veyrié is with the Centre National d'Études Spatiales, Toulouse 31400, France (e-mail: david.veyrie@cnes.fr).

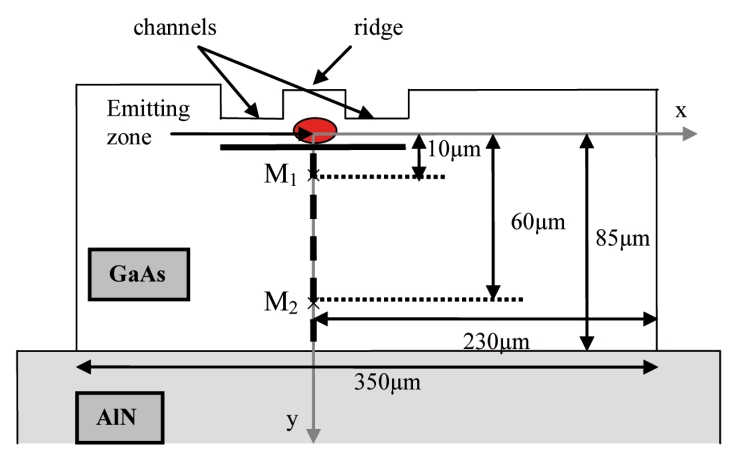

Fig. 1. Generic facet view of the laser diode.

technique to be used for temperature mapping. Then, we use thermoreflectance (TR), which is a fast and very accurate technique, to compare the temperature variation for both structures in different locations of the output facet with a micrometric spatial resolution. Hence, for the first time, we can detail the influence of the UPW length on the temperature both far from the active region and close to it, where a COD is most likely to occur.

\section{EXPERIMENTAl SET Up AND DEVICES Under TeST}

The devices under test (fig.1) are single AlGaAs/InGaAs quantum well laser diodes emitting at $980 \mathrm{~nm}$ used for amplification in optical communication transmission systems [7]. The $3.9 \mathrm{~mm}$ long ridge structure, covered by a gold layer, allows to confine the current and the light emission in the quantum well of the active region at the p-n junction.

We studied two kinds of devices, differing by their UPW length, either short (noted S-UPW) or long (noted L-UPW). The S-UPW is much smaller than the $30 \mu \mathrm{m}$ long UPW studied in [3] whereas the L-UPW has been lengthened with a diode power reduction limited to $1 \%$ at maximum. The diodes are biased using a ITC510 current source, to adjust the operating point, connected with a $33250 \mathrm{~A}$ voltage generator to modulate the driving current which is a $50 \%$ duty cycle square current $(\mathrm{f}=442 \mathrm{~Hz})$ varying from $0.1 \mathrm{~mA}$ to $\mathrm{I}_{\max } ; \mathrm{I}_{\max }$ can be adjusted from $6 \mathrm{~mA}$ to $1 \mathrm{~A}$. This induces a temperature variation $\Delta \mathrm{T}$, hence a reflectivity relative variation $\Delta R / R$ :

$$
\frac{\Delta R}{R}=\frac{1}{R} \frac{\partial R}{\partial T} \Delta T=\kappa \Delta T
$$

where $\mathrm{R}$ is the sample mean reflectivity and $\kappa$ is the thermoreflectance coefficient mainly depending on the nature 


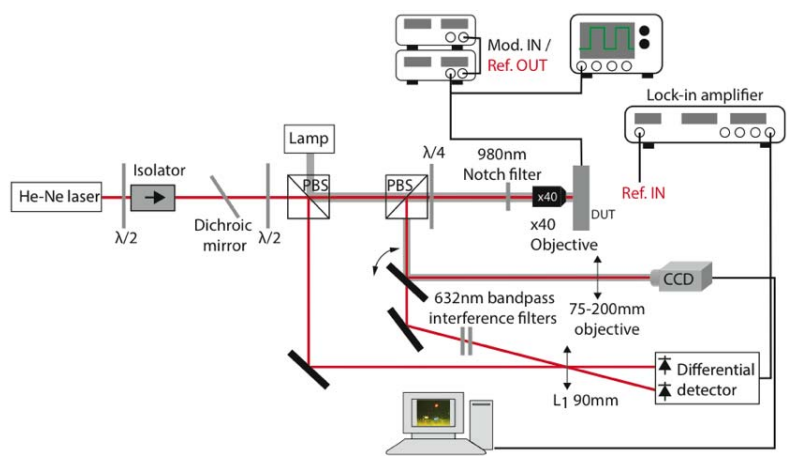

Fig. 2. Thermoreflectance set-up.

of the material and on the probe light wavelength. The total reflectivity can be written as:

$$
R=R_{0}+\Delta R
$$

where $R_{0}$ is the reflectivity signal at room temperature and $\Delta \mathrm{R}$ is the reflectivity variation due to temperature variation:

$\Delta R=\Delta R_{0}+\Delta R_{f} \cos (2 \pi f t+\varphi)+$ higher frequency terms

with $\Delta \mathrm{R}_{0}$ the $\mathrm{DC}$ reflectivity variation due to the DC dissipated power, $\Delta \mathrm{R}_{\mathrm{f}}$ the reflectivity variation due to the dissipated power at frequency $\mathrm{f}, \varphi$ the thermal phase shift at frequency f. "higher frequency terms" includes all the reflectivity variations due to the dissipated power at harmonics $2 \mathrm{f}, 3 \mathrm{f}$... Since the power is mainly dissipated at frequency $\mathrm{f}$, we measure $\Delta R_{f} / R$ to evaluate the $\Delta T_{f}$ temperature variation at frequency $f$.

Among thermal mapping methods, thermoreflectance [8], [9] is an accurate, spatially resolved, non-contact and non-invasive method. The reflectivity variation implies an intensity variation of the light reflected to the photodetector. Thus, measuring the relative variation of detector photocurrent $\Delta \mathrm{I} / \mathrm{I}$, we deduce $\Delta \mathrm{R}_{\mathrm{f}} / \mathrm{R}$ and then $\Delta \mathrm{T}_{\mathrm{f}}$ if $\kappa$ is known. The set-up is presented in fig.2. The probe laser beam first crosses a Faraday isolator coupled to a half wave plate to eliminate a possible probe laser signal coming back into the laser cavity and to adjust the laser intensity. Then, it is separated into a reference beam and a probe beam using a polarizing beam splitter (PBS). The probe beam is then focused on the sample surface through a $\times 40$ magnitude microscope objective. After reflection, the probe beam is transmitted towards the detection arm by a second PBS and focused on the differential detector. A removable mirror sends the reflected probe and the light coming from a white lamp to a CCD camera to visualize the probe position on the sample surface. A dichroic mirror prevents the diode signal from back reflections inside the probe laser cavity. In addition, a 980nm notch filter and two $632 \mathrm{~nm}$ interferential filters are used so that only the probe wavelength could be transmitted to the differential detector. This detector eliminates the DC component dominating the reflected signal, the reference signal input being adjusted by a half wave plate to compensate the DC reflected signal. Then the differential

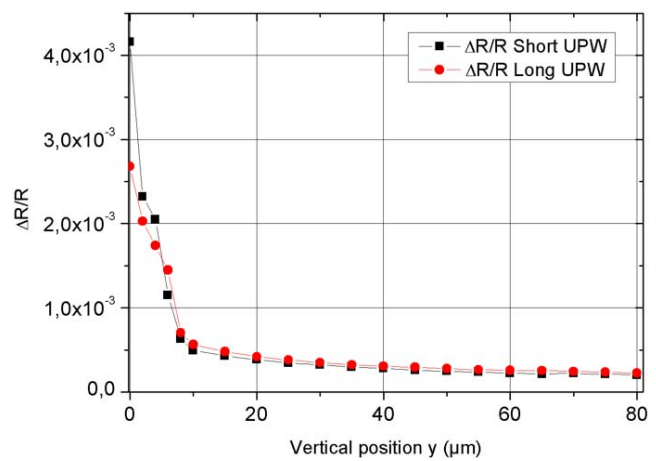

Fig. 3. $\Delta \mathrm{R} / \mathrm{R}$ signal along the vertical $\mathrm{y}$-axis from source to base at $800 \mathrm{~mA}$.

signal is measured by a lock-in amplifier locked at $\mathrm{f}$ to extract $\Delta \mathrm{R}_{\mathrm{f}}$. We also measure the total reflectivity $\mathrm{R}$ to deduce $\Delta R_{f} / R=\kappa \Delta T_{f}$. The differential detector also enables to avoid a possible lock-in amplifier input saturation and to eliminate possible experimental noise sources affecting both reference and reflected beams. Subsequently, $\Delta R_{f} / R$ is simply noted $\Delta \mathrm{R} / \mathrm{R}$.

Since $\kappa$ is wavelength dependent, we had first compared the TR signal measured on the diode facet for different laser probe wavelengths, namely $408,532,632$ and $835 \mathrm{~nm}$. The maximum signal had been obtained for the $632 \mathrm{~nm}$ wavelength. Subsequently, a He-Ne laser was chosen as a probe for all the measurements presented. The spot diameter was evaluated to $3 \mu \mathrm{m}$ approximately and the $\Delta \mathrm{R} / \mathrm{R}$ set-up sensitivity was measured to be as low as $2 \times 10^{-6}$.

\section{Temperature Variation Measurements}

The measurements are done on 3 laser diodes of each type, and for each one, they are repeated three times. The results are the mean values obtained on each kind of diodes. To evaluate the UPW length influence on the output facet temperature variation, we first measured the TR signal along the $y$ axis when $I_{\max }=800 \mathrm{~mA}$ (fig.3). The first point (taken as $y=0$ ) is just under the emitting source towards the AlN heat sink. The displacement step is $2 \mu \mathrm{m}$ on the first $10 \mu \mathrm{m}$ and then $5 \mu \mathrm{m}$ between $\mathrm{y}=10 \mu \mathrm{m}$ and $80 \mu \mathrm{m}$. Close to the source (from $\mathrm{y}=0$ to $5 \mu \mathrm{m}$ ), the S-UPW diode is heating more than the L-UPW one, with a difference reaching almost $40 \%$ for $\mathrm{y}=0$. Then, beyond $5 \mu \mathrm{m}$, the L-UPW diode heats more than the S-UPW one from $20 \%$ at $\mathrm{y}=6 \mu \mathrm{m}$ down to less than $10 \%$ at $80 \mu \mathrm{m}$. The maximum $\Delta \mathrm{R} / \mathrm{R}$ measured at $\mathrm{y}=0$ was $\left(4.160 \times 10^{-3} \pm 2 \times 10^{-6}\right)$ and $\left(2.680 \times 10^{-3} \pm 2 \times 10^{-6}\right)$ for the S-UPW and L-UPW diodes respectively. The uncertainty corresponds to the repeatability error. Other measurements, made along the black horizontal full line, for $\mathrm{y}=5 \mu \mathrm{m}$ and between $\mathrm{x}=-20 \mu \mathrm{m}$ and $\mathrm{x}=20 \mu \mathrm{m}$, confirmed that on the active region and in its close vicinity (closer than $5 \mu \mathrm{m}$ ), the S-UPW laser diode heats more by $20 \%$ than the L-UPW laser diode, in accordance with simulation results [4]. On the contrary, when moving away from the active zone, the S-UPW diode signal becomes lower than the L-UPW diode one with a $10 \%$ difference. The thermal power seems then to be dissipated differently: for the S-UPW diodes, the heating 


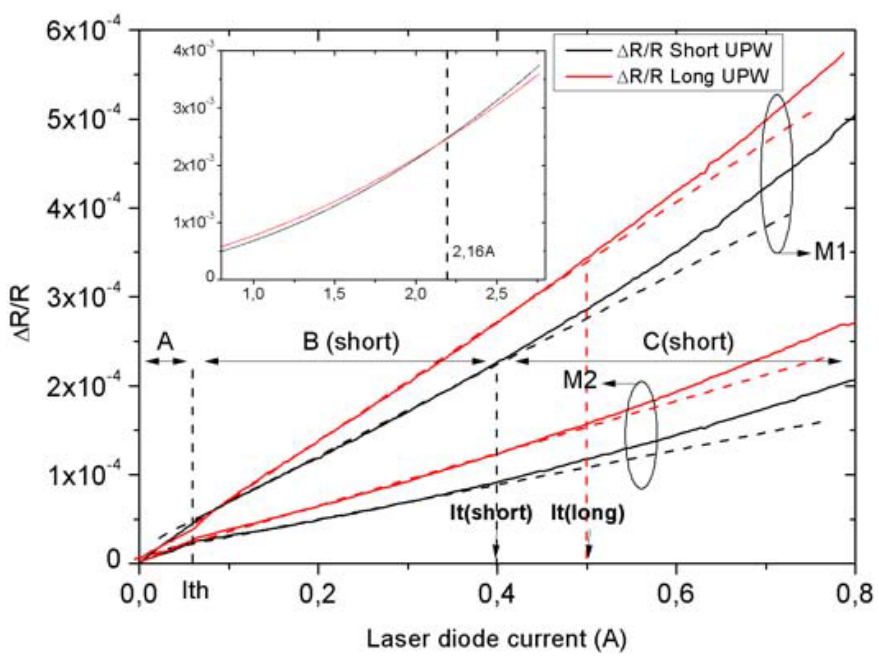

Fig. 4. $\Delta R / R$ signal for two positions $\left(M_{1}\right.$ and $\left.M_{2}\right)$. Zones $B$ and $C$ correspond to the short UPW diode. Dashed lines correspond to the linear fit between $\mathrm{I}_{\mathrm{th}}$ and $\mathrm{I}_{\mathrm{t}}$. Inset: extrapolation for high currents.

is more concentrated on the active region whereas, for the L-UPW diodes, it spreads on the whole facet, being more homogeneously distributed.

Then, we particularly focused on two particular positions: one close $(10 \mu \mathrm{m})$ to the emitting source $\left(\mathrm{M}_{1}\right)$ and one $60 \mu \mathrm{m}$ far from it $\left(\mathrm{M}_{2}\right)$ as indicated in fig.1. For each position, we measured the TR signal as a function of the current, $\mathrm{I}_{\max }$ varying from $6 \mathrm{~mA}$ to $800 \mathrm{~mA}$ with a $3 \mathrm{~mA}$ step (fig.4). We distinguish three zones. The first one (zone A), under the threshold, has a linear behavior with a slope $\alpha_{1}$. Then, between the threshold and a transition current $\mathrm{I}_{\mathrm{t}}$ (zone $\mathrm{B}$ ), the behavior is still linear but with a different slope $\alpha_{2}$. Finally, in the last zone $\mathrm{C}$ beyond $\mathrm{I}_{t}$, the behavior appears non-linear. This can result in a fast and strong temperature increase and then in a COD at very high current.

From a thermal point of view, three contributions can be considered in the facet temperature variation [10]. The first one is due to the conversion of the electrical power into heat and is the only active contribution under the threshold. Starting above the laser threshold, part of the input electrical power is extracted as optical output thus reducing the temperature slope: this is the second contribution. The last contribution comes from the surface heat source which creates a new temperature increase and can lead to a huge thermal runaway rapidly inducing a COD since it is concentrated on the emission area and its amplitude strongly increases with the current. This last contribution is then negligible at low current (A and B zones) and far from the active region (at $\mathrm{M}_{2}$ ). But when approaching the active region at $\mathrm{M}_{1}$, it becomes dominant, even at relatively low current (zone B), and can compensate the second contribution, finally leading to a temperature increase in zone B. The $\alpha_{2} / \alpha_{1}$ ratio is then an indicator of the facet heating.

For position $\mathrm{M}_{2}$, as expected, $\alpha_{2} / \alpha_{1}$ is smaller than 1 since a part of the electrical power injected is converted into light and hence the proportion of the electrical power converted into heat decreases. Then, in zone $C$, the TR signal increases faster because of the surface source whose amplitude strongly increases with the supplied current. At this position, the L-UPW diode heats more than the S-UPW one, in agreement with fig.3. For position $\mathrm{M}_{1}$, the L-UPW diode still heats more than the S-UPW one. When moving from $\mathrm{M}_{2}$ to $\mathrm{M}_{1}$, the $\alpha_{2} / \alpha_{1}$ ratio increases from 0.54 to 0.7 for the S-UPW diode and from 0.67 to 1.18 for the L-UPW one. Hence, for both kinds of diodes, when approaching the emitting zone, the surface source contribution increases but, in the last case (L-UPW at position $\mathrm{M}_{1}$ ), the surface source contribution is clearly dominating, which is consistent with the previous results showing that beyond $5 \mu \mathrm{m}$ from the source, the L-UPW diode heats more than the other one.

To determine which UPW will be more sensitive to COD, the non-linear behavior needs to be analyzed in detail since COD will occur at very high current well beyond $800 \mathrm{~mA}$, i.e. far away in the non-linear zone $\mathrm{C}$. The $\mathrm{I}_{\mathrm{t}}$ current, indicating the onset of the non-linear behavior (which leads to thermal runaway), is evaluated to $500 \mathrm{~mA}$ for the L-UPW diode but only $400 \mathrm{~mA}$ for the S-UPW diode (fig.4), hence $20 \%$ lower. In addition, we fitted the curves by a polynomial fit in the $\mathrm{I}_{\mathrm{t}}-0.8 \mathrm{~A}$ range and extrapolated them at very high current up to $2.75 \mathrm{~A}$ (inset in fig.4). We then observe that the non-linearity is higher for the S-UPW: the quadratic term is $4.2 \times 10^{-4}$ and $3.3 \times 10^{-4}$ for the S-UPW and L-UPW respectively. As a result, for very high current beyond 2.16A, the S-UPW diode heats more than the L-UPW counterpart. The thermal runaway will then be triggered at lower current. We confirm it measuring the optical power as a function of the current until the COD arises. It occurred at $2.65 \mathrm{~A}$ for the S-UPW diode whereas for the L-UPW one, the COD was not yet reached at $3 \mathrm{~A}$.

All the measurements lead to the conclusion that the L- UPW diode heats a little bit more than the S-UPW one for low currents and far from the source (beyond $5 \mu \mathrm{m}$ from it). However, the temperature variation is much higher (up to $40 \%$ ) for the S-UPW diodes in the source close vicinity and at high currents. In addition, for currents above $I_{t}$, the temperature variation becomes non-linear for both kinds of diodes but it increases more rapidly for the short UPW diode. These S-UPW diodes may then be less reliable at very high current and should be more sensitive to COD.

Other papers have studied the influence of unpumped windows on laser diode reliability, either by simulation [4] or experimentally [3], [11]. In [11], Ohgog and al studied the effect of a current blocking region on the light output power and on the driving current. In [3], Rinner uses $\mu$-Raman spectroscopy to evaluate the facet and averaged waveguide temperatures. It is quite difficult to compare their results with ours because, concerning Ohgoh, the laser diode structure he studied is very different. As for Rinner, he shows a reduction of the facet overheating due to the unpumped window much larger than the one we have measured. One of the possible explanations might be that the measurements are not performed at the same position since we have measured under the emitting zone while he has investigated directly on it. Moreover, $\mu$-Raman measurements reported large uncertainties (up to $\pm 50 \%$ ) [3], [6]. Nevertheless, all these studies lead to the same conclusion that a long unpumped window improves the laser diode reliability, especially by increasing the COD threshold. Our study confirms these results but also 
shows for the first time and with a very good accuracy, how the thermoreflectance signal, hence the temperature variation, is spatially distributed on the output facet.

\section{REFERENCES}

[1] M. Fukuda, M. Okayasu, J. Temmyo, and J. Nakand, "Degradation behavior of $0.98-\mu \mathrm{m}$ strained quantum well InGaAs/AlGaAs lasers under high-power operation," IEEE J. Quantum Electron., vol. 30, no. 2, pp. 471-476, Feb. 1994.

[2] H. Horie, Y. Yamamoto, N. Arai, and H. Ohta, "Thermal rollover characteristics up to $150{ }^{\circ} \mathrm{C}$ of buried-stripe type 980-nm laser diodes with a current injection window delineated by a $\mathrm{SiN}_{\mathrm{X}}$ layer," IEEE Photon. Technol. Lett., vol. 12, no. 1, pp. 13-15, Jan. 2000.

[3] F. Rinner et al., "Facet temperature reduction by a current blocking layer at the front facets of high-power InGaAs/AlGaAs lasers," J. Appl. Phys., vol. 93, no. 3, pp. 1848-1850, 2003.

[4] X. Liu, M. H. Hu, C. G. Caneau, R. Bhat, and C.-E. Zah, "Thermal management strategies for high power semiconductor pump lasers," IEEE Trans. Compon. Packag. Technol., vol. 29, no. 2, pp. 268-276, Jun. 2006
[5] P. E. Raad, P. L. Komarov, and M. A. Bettiati, "Thermoreflectance measurements for optically emitting devices," in Proc. 18th Int. Workshop THERMINIC, Budapest, Hungary, Sep. 2012, pp. 1-3.

[6] M. Hempel, J. W. Tomm, T. Elsaesser, and M. Bettiati, "High singlespatial-mode pulsed power from $980 \mathrm{~nm}$ emitting diode lasers," Appl. Phys. Lett., vol. 101, no. 19, pp. 191105-1-191105-5, 2012

[7] M. A. Bettiati, "High optical strength GaAs-based laser structures," Microelectron. Rel., vol. 53, nos. 9-11, pp. 1496-1500, 2013.

[8] S. Dilhaire, S. Grauby, and W. Claeys, "Thermoreflectance calibration procedure on a laser diode: Application to catastrophic optical facet damage analysis," IEEE Electron Device Lett., vol. 26, no. 7, pp. 461-463, Jul. 2005.

[9] P. W. Epperlein, "Mapping of local temperatures on mirrors of GaAs/AlGaAs laser diodes," Inst. Phys. Conf. Ser., vol. 112, chapter 8, pp. 633-638, 1990.

[10] S. Dilhaire, S. Grauby, S. Jorez, L.-D. P. Lopez, E. Schaub, and W. Claeys, "Laser diode COFD analysis by thermoreflectance microscopy," Microelectron. Rel., vol. 41, nos. 9-10, pp. 1597-1601, 2001.

[11] T. Ohgoh, T. Fukunaga, and T. Hayakawa, "Technologies and applications of Al-free high-power laser diodes," Elect. Eng. Jpn., vol. 158, no. 1 , pp. 53-59, 2007 